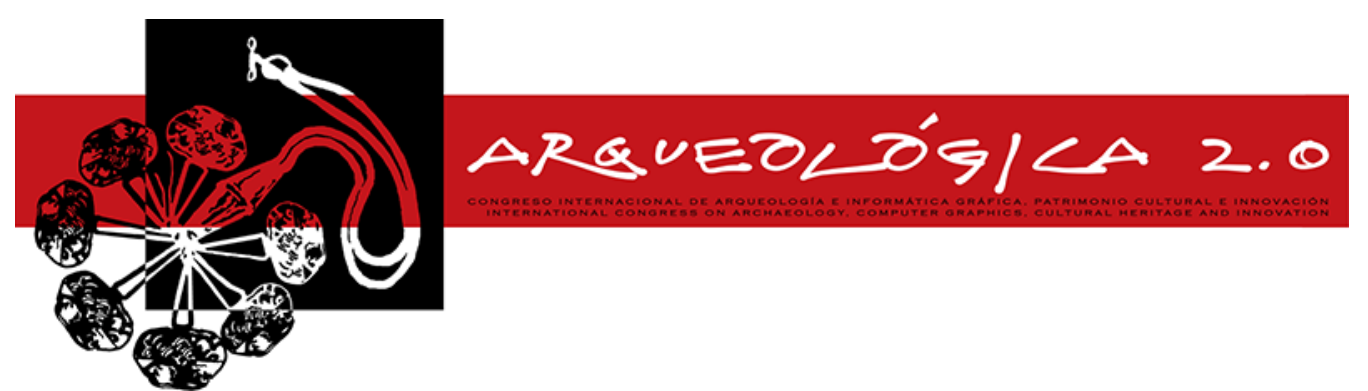

Proceedings of the $8^{\text {th }}$ International Congress

on Archaeology,

Computer Graphics,

Cultural Heritage and Innovation

'ARQUEOLÓGICA 2.0'

in Valencia (Spain),

Sept. $5-7,2016$

DOI: http://dx.doi.org/10.4995/arqueologica8.2016.3659

Received: $15 / 03 / 2016$

Accepted: 09/05/2016

\title{
CONSERVATION MODEL FOR BASILICA OF SMYRNA AS AN THEORETICAL INTENTION
}

\author{
Tugba Saricaoglu \\ Department of Architectural Restoration, University of Dokuz Eylul, Izmir, 35290, Turkey. tugbasaricaogluts@gmail.com
}

\begin{abstract}
:
History is the space of the time and also an accumulation of knowledge. This accumulation transforms into layers, layers provides knowledge. Also, historical envaronen has undeniable importance due to knowledge it has especially when it comes to architecture. Historical enviroment is like an architectural laboratuary which provides knowledge from past to present. That gives the reason why historical environment should be analyzed, preserved, rehabilited and restored in the first place. Sustainabilty of the knowledge can be supported by studying historical enviroment in every field. The main focus of this reasearch is integrating Baslica of Agora in Smyrna into today by analysing its cultural, historical and physical situation. Before the integration of the Basilica, information should be gathered and documentions related to the building and its close vicinty should be concluded. Documentation generated (measured and drawn) of the whole basilica in order to develope intervention decisions on scientific platform in any scale. Therefore, intervention orders took place on both whole basilica and the main intervention part of basilica as a modulatible scale. Basilica of the agora in Smyrna ancient city which has never been architecturally studied, documanted by using advanced technics surveying methods. Using all the data from documentation and academic studies 35. and 36. axles of the basilica determined to be the definite place where intervention orders -determined by analitical studies on whole scale of the basilica and detailed studies on the axles- took place.
\end{abstract}

Key words: basilica of Symrna, digital archaeology, cultural heritage, 3D documentation, 3D survey

\section{Introduction}

Historical enviroment is like an architectural laboratuary which provides knowledge from past to present. That gives the reason why historical enviroment should be analyzed, preserved, rehabilited and restored in the first place. Studying historical enviroment in every field can support sustainabilty of the knowledge.

Basilica of the Smyrna is the one of the most interesting Roman basilicas (Akurgal 2002), 2nd century BC, which has significiant scale (161,4 meters to 29,3 meters) and also original graffito (Taslialan and Drew-Bear 2004) (Fig. 1) on its cryptoporticus walls (Fig. 2). The ultimate purpose of this reasearch is integrating Baslica of Agora in Smyrna into today by analysing its cultural, historical and physical situation using digital methods to survey it. Even this integration will be theoretical it will be a method and survey model for the future studies which will be not just theoric but also practicable hopefully.

In this article analitical process of defining conservative problems of the basilica will be discussed to explain which part of the basilica studied.

\section{Identifying the Area of Intervention}

Documentation of the building made by using terrestrial laser scanner (Saricaoglu 2015) (TLC)-Faro Focus 3D S
120) (Fig. 3). The pointcloud of the building scanned up to 200 scans and two different scan durations- 9 minutes and 16 minutes, and took ten days. These time differences were decided accordingly detail of the elements of the ruins. In other words, cryptoporticus walls which has graffito remnant was scanned for 16 minutes, the other part of the basilica scanned in 9 minutes per scan for 200 scans. Pointcloud data (Figs. 4 and 5) developed and used to generate orthopoint data (Fig. 6). Subsequently, CAD based drawings of the building made from generated data.

Conservation problems evaluated after documentation of the building exclusievely. The model intervention area (Fig. 7) is decided according to those conservative issues which are conservative problems, structural problems, and awareness problems of the building.

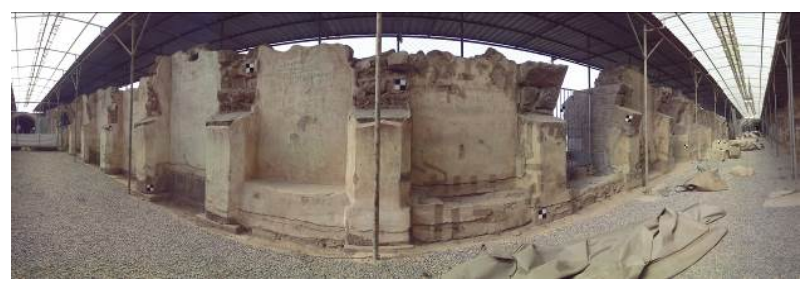

Figure 1: Grafito on cryptoporticus wall. 


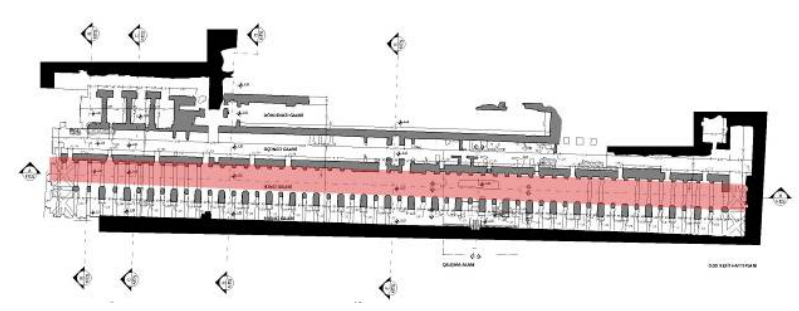

Figure 2: Cryptoporticus wall (second gallery).

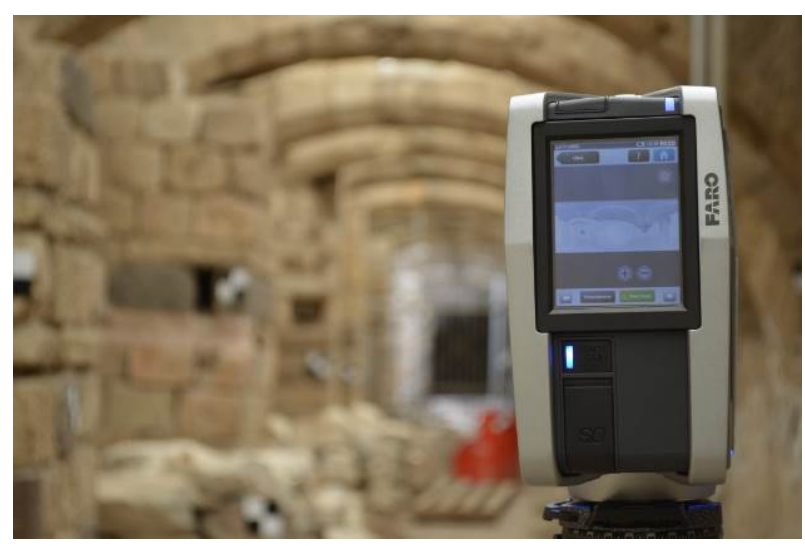

Figure 3: Faro Focus 3D S 120.

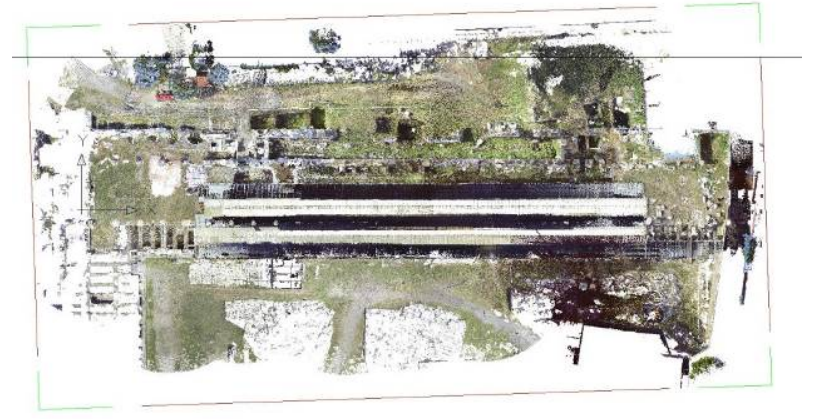

Figure 4: Pointcloud data of the basilica and its near surroundings.

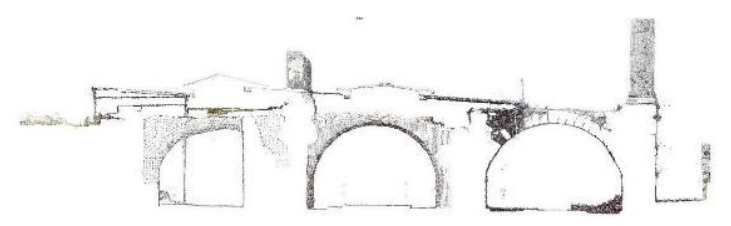

Figure 5: Pointcloud data of the basilica as a section sample.

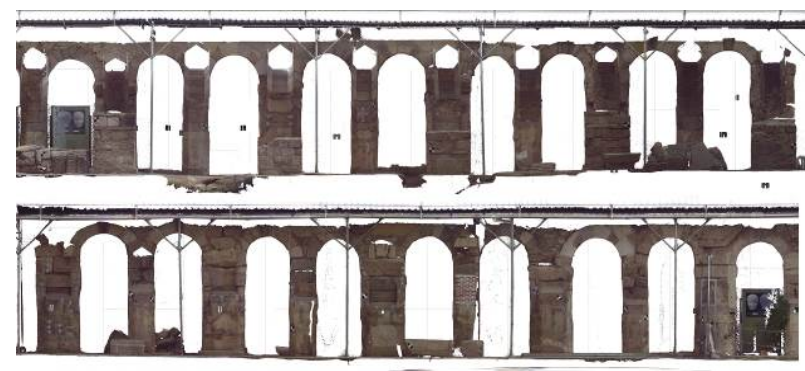

Figure 6: Orthopoint samples of the basilica.

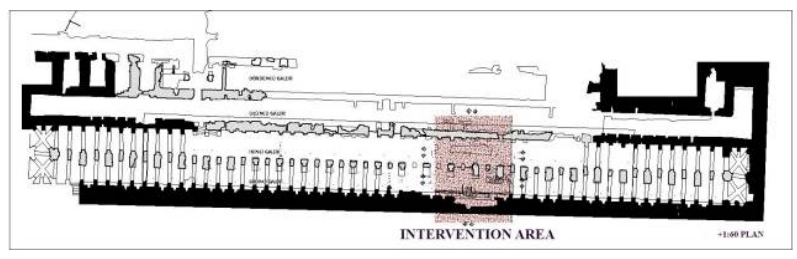

Figure 7: Intervention area.

\subsection{Evaluation of the Conservation Problems}

Revealing the conservation problems of the agora, which is the area it takes place in, is required before determining the conservation issues of basilica in order to generate intervention model.

Site usage and visitor guidance not being consistent with urban archeological site planning and does not provide legal conformity (Yaka 2006) is determined as the one of the primary problem. Today entrance of the agora is placed agora for employees and visitors (Ipekoglu and Uygun 2011) is in the south of the area. The only planning (not be projected) including field management and guidance construction on agora is the foresight of taking the visitor entrance from north street, basement of agora and basilica, and after visiting the west stoa, providing the entrance from the Faustina gate of bouleuteron building and the mosaic structure at the west.

In conclusion, general conservation problems are evaluated by integrated approach of the whole site.

\subsection{Conservation Problems of Basilica}

Due to management problems of the site, agora of the Symrna and basilica are becoming very undistinguished both academically and socially. Additionally, due to management problems, considered primary, of the site conservation of the basilica is evaluated under two subtopics namely structural and awareness basically.

\subsection{Structural Problems of Basilica}

Basilica was built in stone masonry technique (also techniques of belt, vault, cross vault etc. masonry, gap passing) matching with its periods (Hellenistic, Roman). The main problem when basilica's material and spatial qualifications evaluated within this scope is that there are material deprivation especially in the bearing elements in consequence of building's being under earth and its being urgently repaired because of the earthquake (Bean 2001), A.D. 178, it earlier on faced with. Although these deprivations are not in a very systematical construct, they are in high level that can affect the holistic stability of the building in long term, as presented in Figure 8.

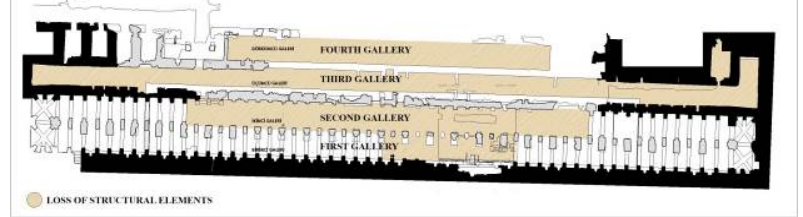

Figure 8: Deprivation of structural elements. 
Another one of the material deprivation of the basilica is the demolished area other than belts. These areas are comprised of walls dividing the galleries and terrace walls, ruins in the area with ladder where a modern metal-made systematic gate was constructed, as presented in Figure 9.

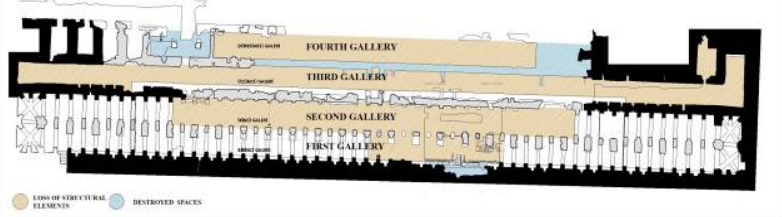

Figure 9: Loss of structural elements and destroyed spaces.

When the structural material deprivation examined systematically, the deprivation of the same bearer axes detected in the first and second gallery, as presented in Figure 10. In addition to this finding, the area where all the material deprivations overlap, most damaged area (Fig. 11), is decided to considerable as one of the intervention model data parameters.

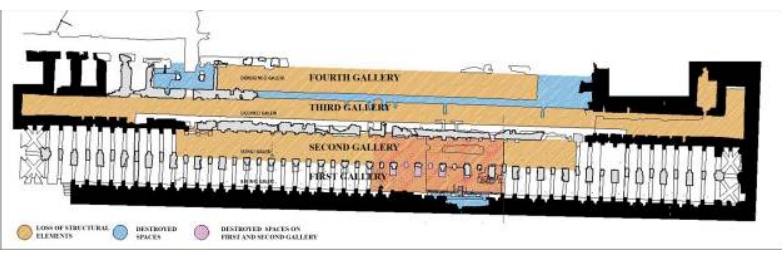

Figure 10: Loss of structural elements on first and second gallery.

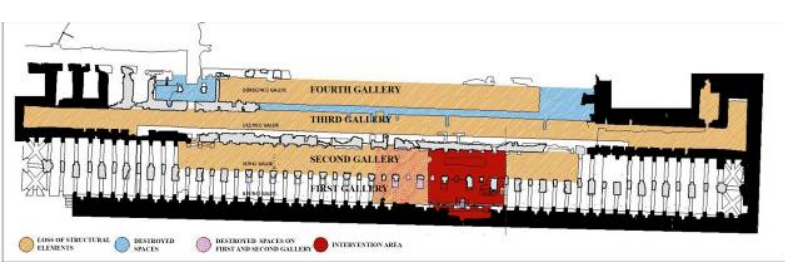

Figure 11: Most structurally damaged area.

\subsection{Awareness Problems of Basilica}

Another problem of the basilica that occurs due to site's management problem is the limited spatial perception of basilica. Hence, the phscical and cultural existence of the building could not be provided and results awareness problems.

Since, basilica's tree-dimentional aspect is not spatially and socially perceptable former interventions that are three-dimentionally made are decrypted. Nothwithstanding, those interventions are made in an urgent manner such as, "save the day" kind of context, they are physically sensible and radical. The one of the interventions are protection roofs (Figs. 12 and 13). The first roof, which covers abutments of the basilica's first and second galleries, made before 2007 after excavation (Ersoy 2010). The second roof is the one built for the covering of the bare places of the ruins in 2007 (Ersoy 2010).

ther intervention is metal doors (Fig 14), in between east and west gaps of the secand gallery. Although metal doors provide entrance to basilica from east and west, the metal ladder that was added to the destroyed wall in the southeast of basilica provides direct entrance to inside (galleries) (Fig. 15). However, as this entrance is demolished during excavation (Ersoy 2010), it was fixed with temporary expedients and only exists for the usage of academic and profecional employees.

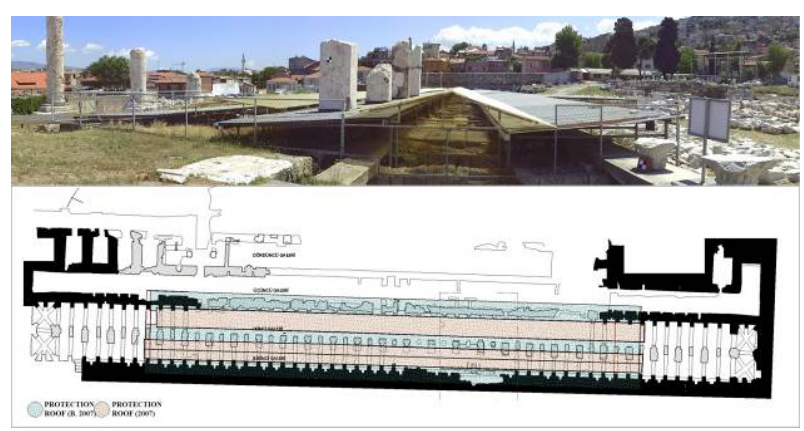

Figure 12: Protection roofs of the basilica.

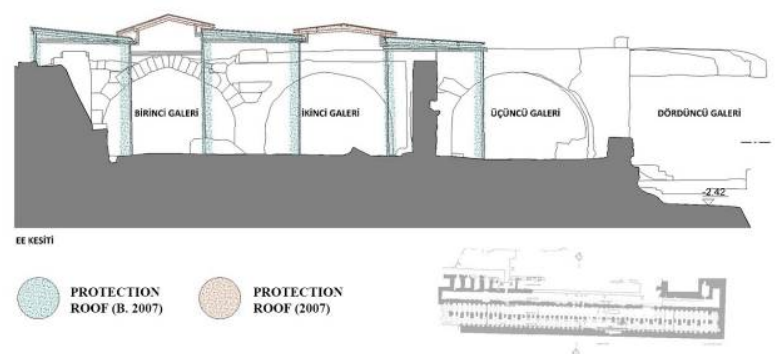

Figure 13: Protection roof sof the basilica, section.

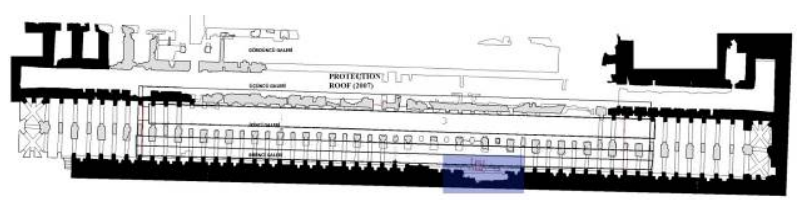

Figure 14: Modern enterance of the basilica.

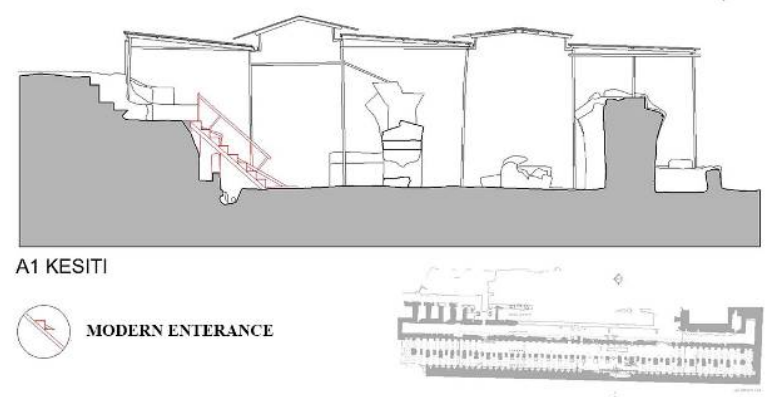

Figure 15: Modern enterance of the basilica, section.

The other intervention is the metal stands which supports belts and abutments (Fig. 16). These strengthenings were made urgently and actually prove basilica's being under a systematic physical threat. One of the other reinforcement is recontraction of eight belts, with little belts in between, are placed in the first gallery (Fig. 17).

Since all these interventions have been made for avoiding structural thaw, they underline the one of the main conservative issues, awareness, as a result of structural problems of the building. All in all, all of the interventions mentioned before creates specific area 
when overlap (Fig. 18), that spatial intersection will be considered second of the intervention model data parameters.

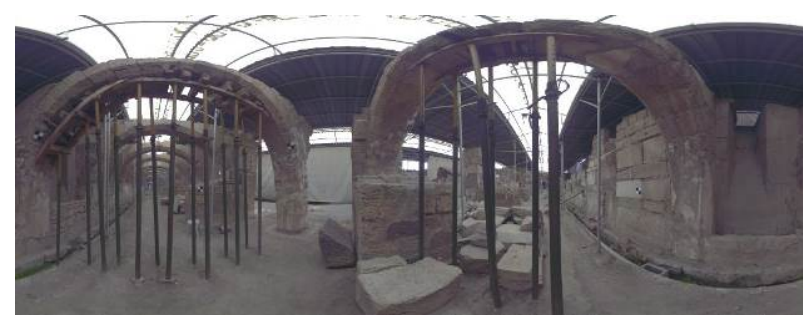

Figure 16: Metal stands to strenght abutments.

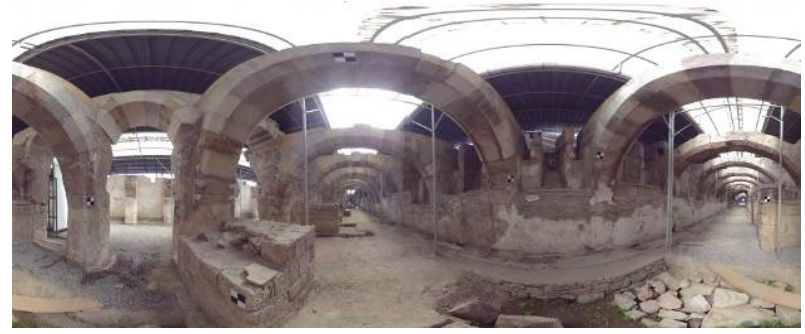

Figure 17: Restorated belts.

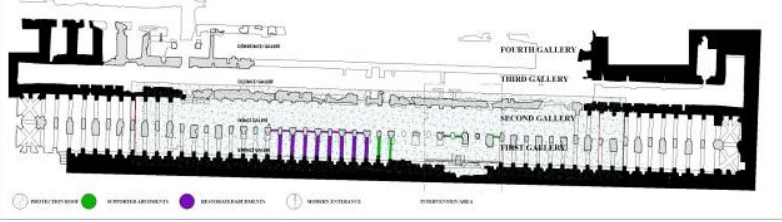

Figure 18: Conservative interventions on site.

\section{Conclusion}

In conclusion, after identifying basilica's conservative issues under the names of, structural, and awareness, modeling sample intervention intersection (Figs. 7 and 19 ) is generated by using those outcomes. Accordingly, sample intervention area is decided to be at the southeast of the basilica and limited with 33th and 38th axes involving the first and the second galleries (Fig. $20)$. The 35th and 36th of these axes have been chosen as an application area, in order to make two different sampling and proving modulation for the future, as presented in Figure 21 and Figure 22.

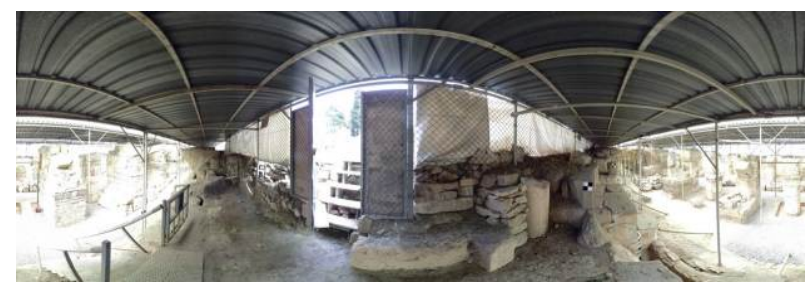

Figure 19: Intervention area, image.

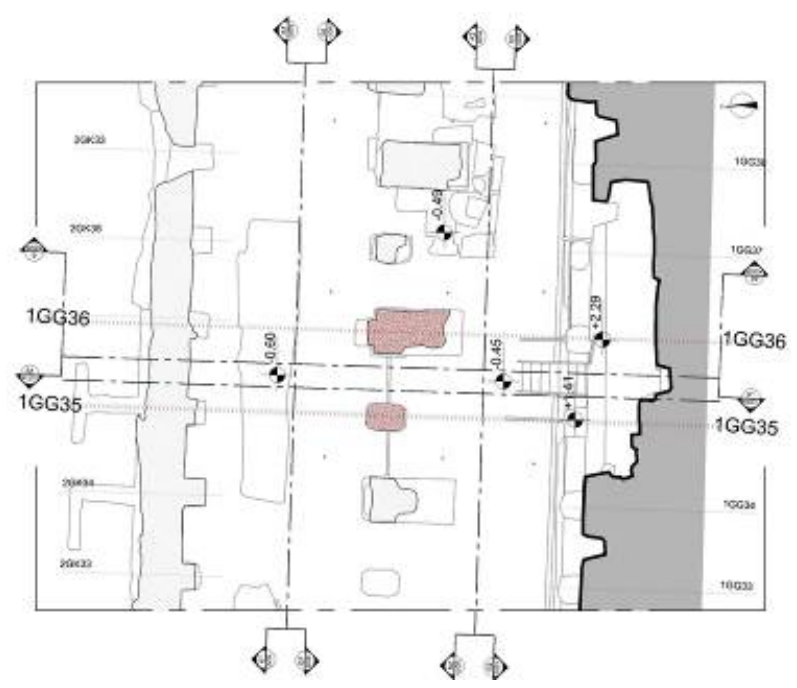

Figure 20: Intervention area, plan.
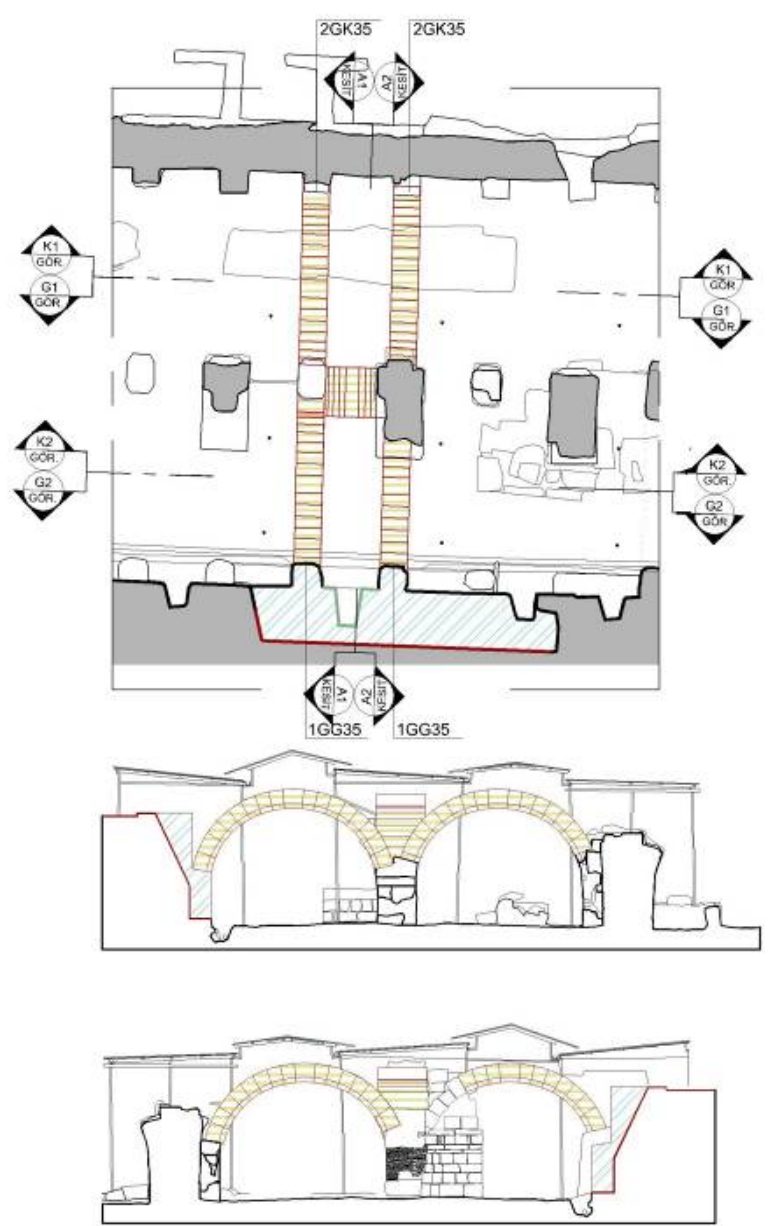

Figure 21: Intervention area, drawing, intervention maping. 


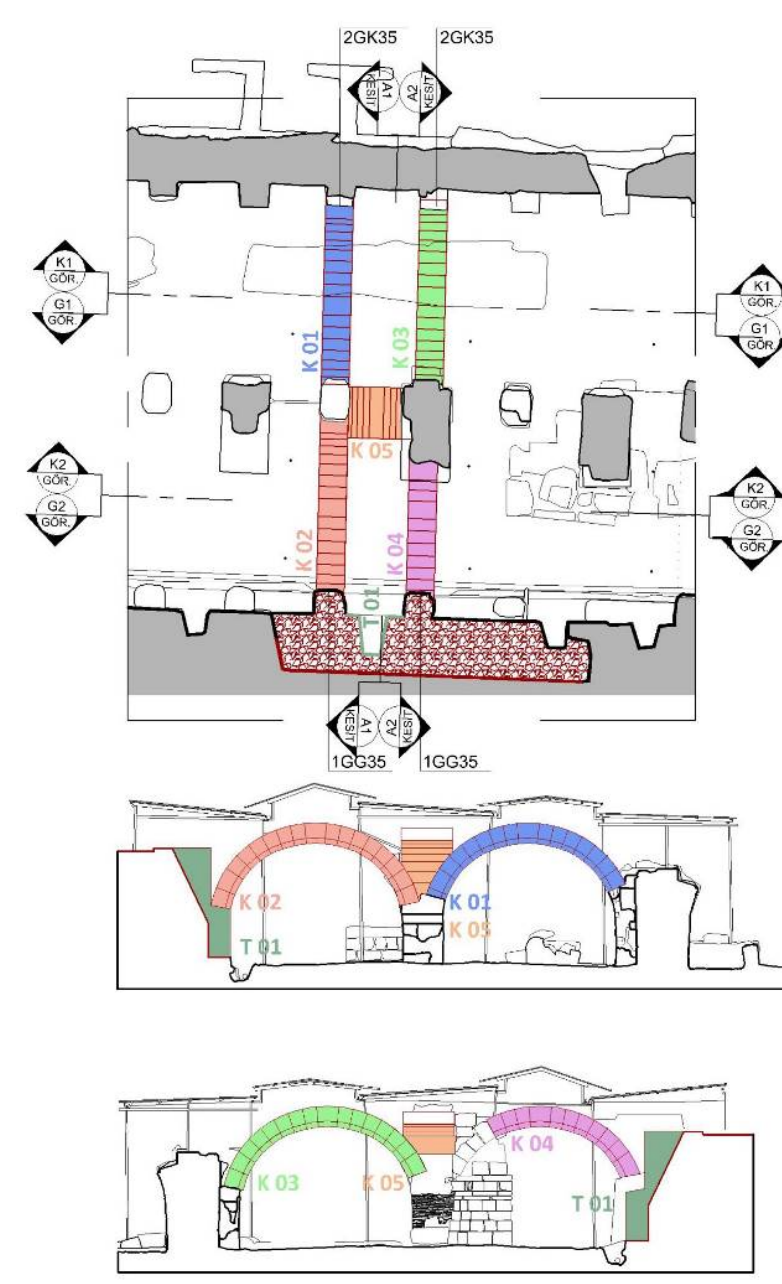

\section{Results and Discussion}

The study mainly focuses on revealing of basilica's conservational problems (along with 3D laser scanner survey and CAD studies of the whole building) after narrating the historical and structural evaluations. Moreover, the main aim of the study is making a model base for the future restoration studies to contribute both therocically and digitally sustaibale knowledge. Within this framework, under the light of digital and theorocial datas partial analytical restoration studies have been developed of the cultural heritage.

\section{Acknowledgements}

This survey studies of the work was funded by the University of Dokuz Eylül under Scientific Research Project named: 'Restoration Studies on Third Nave of Basilica of Smyrna'.

Figure 22: Intervention area, drawing, detailed maping.

\section{References}

AKURGAL, E., 2002. Ancient Civilisations and Ruins of Turkey. İstanbul: Net Turistik, pp. 12-58.

BEAN, G., 2001. Eski Çağda Ege Bölgesi. İstanbul: Arion.

ERSOY, A., 2010. Ancient Smyrna: Archeology in İzmir and Stratigraphy in Ancient City Centre.IN: A.E. GÖKSU, Ş. G. DÜNDAR, eds, Urban hiztorical stratum: From Smyrna to İzmir. İzmir: Dokuz Eylül Üniversitesi Press, pp.131-139.

IPEKOGLU, B. and UYGUN F., 2011. Evaluation of interventions in western stoa of Agora in Izmir. Journal of Cultural Heritage, 42(2), pp.18-25.

SARICAOGLU, T., 2015. Development of Intervention Orders Upon Basilica of Smyrna Agora: 35.-36. Axles. Master Thesis, University of Dokuz Eylül.

TASLIALAN, M. and DREW-BEAR, T. 2004. Rapport sur les Travaux Effectués sur l'agora de Smyrne. Anatolia Antiqua, 12(12), pp 293-308.

YAKA, N.F., 2006. Evaluation of Interventions in Western Stoa of Agora in İmir. Master Thesis, Izmir Institue of Technology. 